\title{
Performance Evaluation of Pressure Transducers for Water Impacts
}

\author{
Gregory J. Vassilakos ${ }^{1}$ and David E. Stegall ${ }^{2}$ \\ Analytical Mechanics Associates, Hampton, Virginia, 23666 \\ and \\ Sean Treadway ${ }^{3}$ \\ Corvid Technologies, Mooresville, North Carolina, 28117
}

\begin{abstract}
The Orion Multi-Purpose Crew Vehicle is being designed for water landings. In order to benchmark the ability of engineering tools to predict water landing loads, test programs are underway for scale model and full-scale water impacts. These test programs are predicated on the reliable measurement of impact pressure histories. Tests have been performed with a variety of pressure transducers from various manufacturers. Both piezoelectric and piezoresistive devices have been tested. Effects such as thermal shock, pinching of the transducer head, and flushness of the transducer mounting have been studied. Data acquisition issues such as sampling rate and anti-aliasing filtering also have been studied. The response of pressure transducers have been compared side-by-side on an impulse test rig and on a 20-inch diameter hemisphere dropped into a pool of water. The results have identified a range of viable configurations for pressure measurement dependent on the objectives of the test program.
\end{abstract}

\section{Nomenclature}

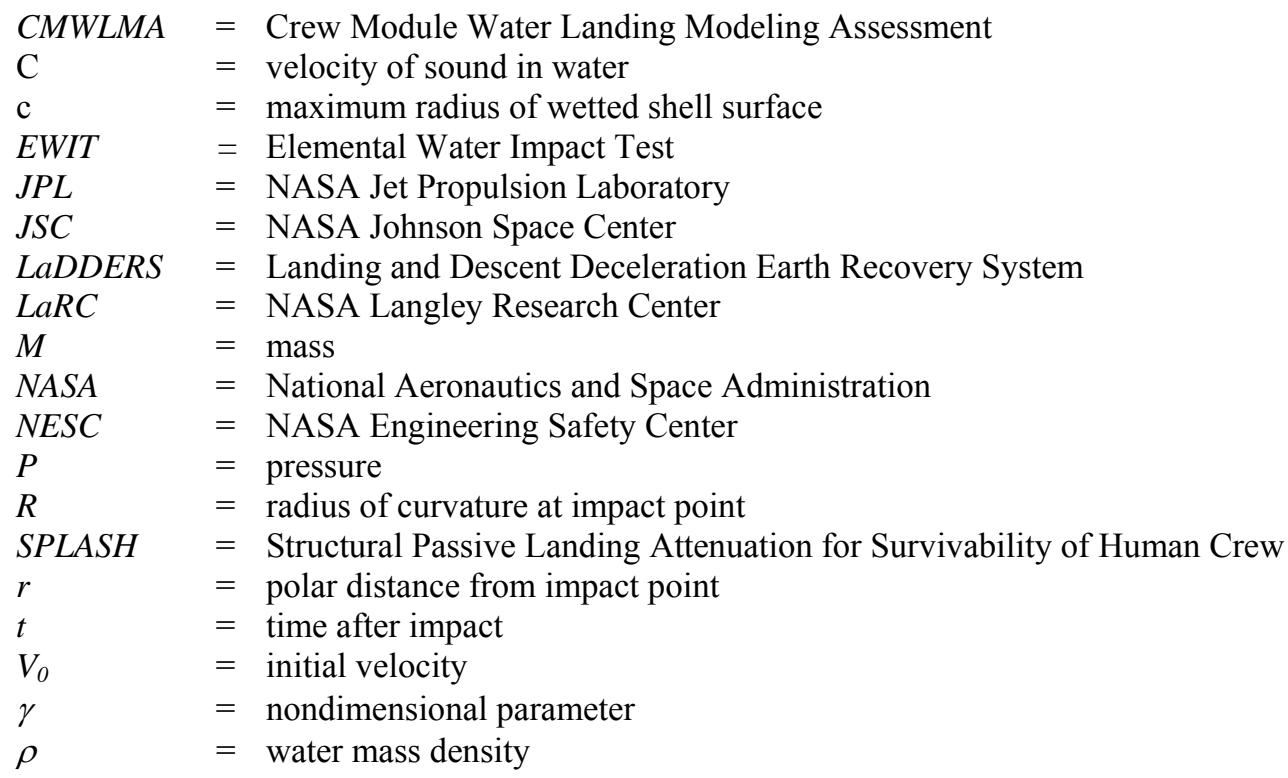

\footnotetext{
${ }^{1}$ Engineer, NASA Langley Research Center, Structural Dynamics Branch, Mail Stop 230.

${ }^{2}$ Test Engineer, NASA Langley Research Center, Structural Dynamics Branch, Mail Stop 495.

${ }^{3}$ Research Engineer, Corvid Technologies.
} 


\section{Introduction}

$\mathrm{T}$ HE Orion Multi-Purpose Crew Vehicle is being designed for water landings similar to Apollo. Apollo relied upon an extensive test program to demonstrate the structural integrity of the crew module during water landing impacts. Orion is relying upon extensive use of computer simulations with only limited testing. The focus of the test program is to obtain data to benchmark the ability of the computer simulations to predict water landing loads. The test program is predicated on the reliable measurement of impact pressure histories. The test program will culminate with full-scale mock-ups and an early production prototype being drop-tested in a water basin. The test program began more modestly with the Phase 1 Elemental Water Impact Test (EWIT) series, which features a 20inch diameter hemisphere dropped into a pool of water. The hemisphere is outfitted with an accelerometer and an array of pressure transducers. This test article has served as a test bed for evaluating the performance of pressure transducers types, mounting configurations, and Data Acquisition System (DAS) parameters. In addition to the EWIT test series, table top tests were performed to evaluate the response of the pressure transducers to known shocks and to changes in temperature.

\section{Experimental Set-Ups}

\section{A. Water Impact Test}

Drop tests were performed in a 15-foot diameter above-ground swimming pool located in the high-bay area of Building 1293A at the National Aeronautics and Space Administration (NASA) Langley Research Center (LaRC). The depth of the water in the pool was approximately four feet. The test pool was located inside a 24-foot diameter above-ground swimming pool to catch any over splash. A foam pad was placed under the liner at the bottom of the inner pool to cushion bottom impacts. The test article was suspended above the test pool on a boom extended from a forklift. A line hanging from the test article was used to measure the drop height. The test set-up is illustrated in Figure 1.

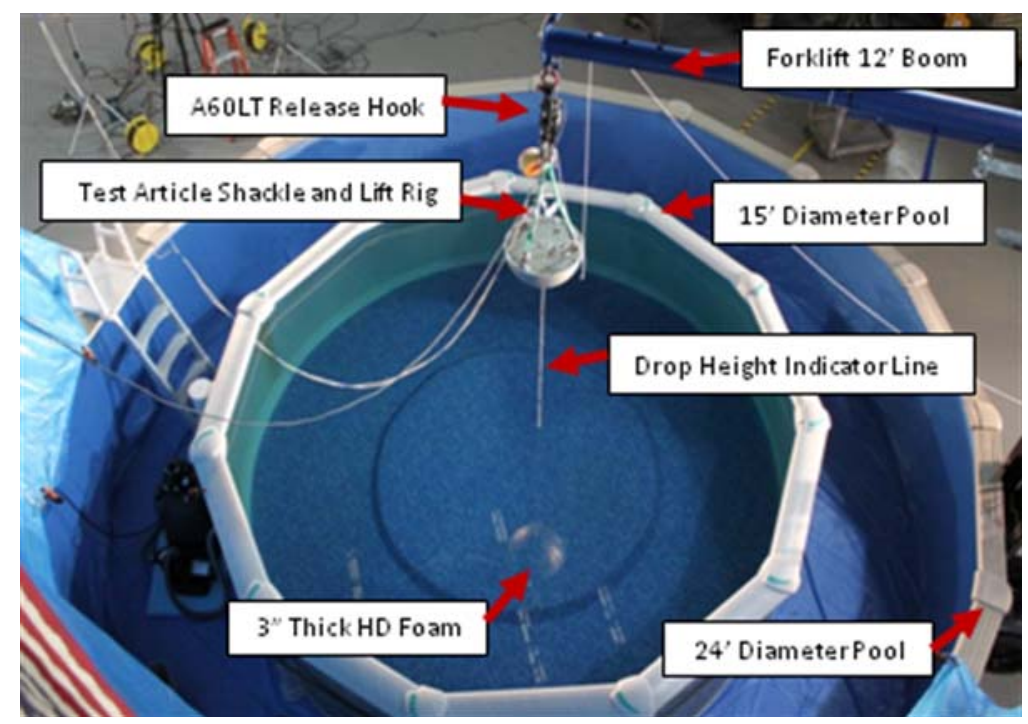

Figure 1. Test Set-Up.

The penetrometer test article is a hemispherical aluminum shell with an outside diameter of 20 inches. The general configuration of the penetrometer is illustrated in Figure 2. The penetrometer has a shell thickness of 0.19 inches and is filled with bismuth ballast to an approximate depth of 2.5 inches at the apex. Eight phenolic ribs intersect and provide an internal attachment point for an accelerometer at the center. The penetrometer was outfitted with an arrangement of pressure transducers that was augmented as the test series progressed. The baseline arrangement featured three pressure transducers arranged on a circle centered at the apex, with a radius of approximately 2.25 inches as illustrated in Figure 3. As the test series progressed, additional pressure transducers were added at the same radius and along a radial line extending out from the apex. An aluminum lid with a 
thickness of 0.25 inches serves to keep water away from the instrumentation. The penetrometer is considered rigid as structural flexibility does not play a significant role in the response. The penetrometer is lifted into position for the drop test via three lift points at the perimeter of the lid. The weight of the penetrometer with instrumentation is $48 \mathrm{lb}$.

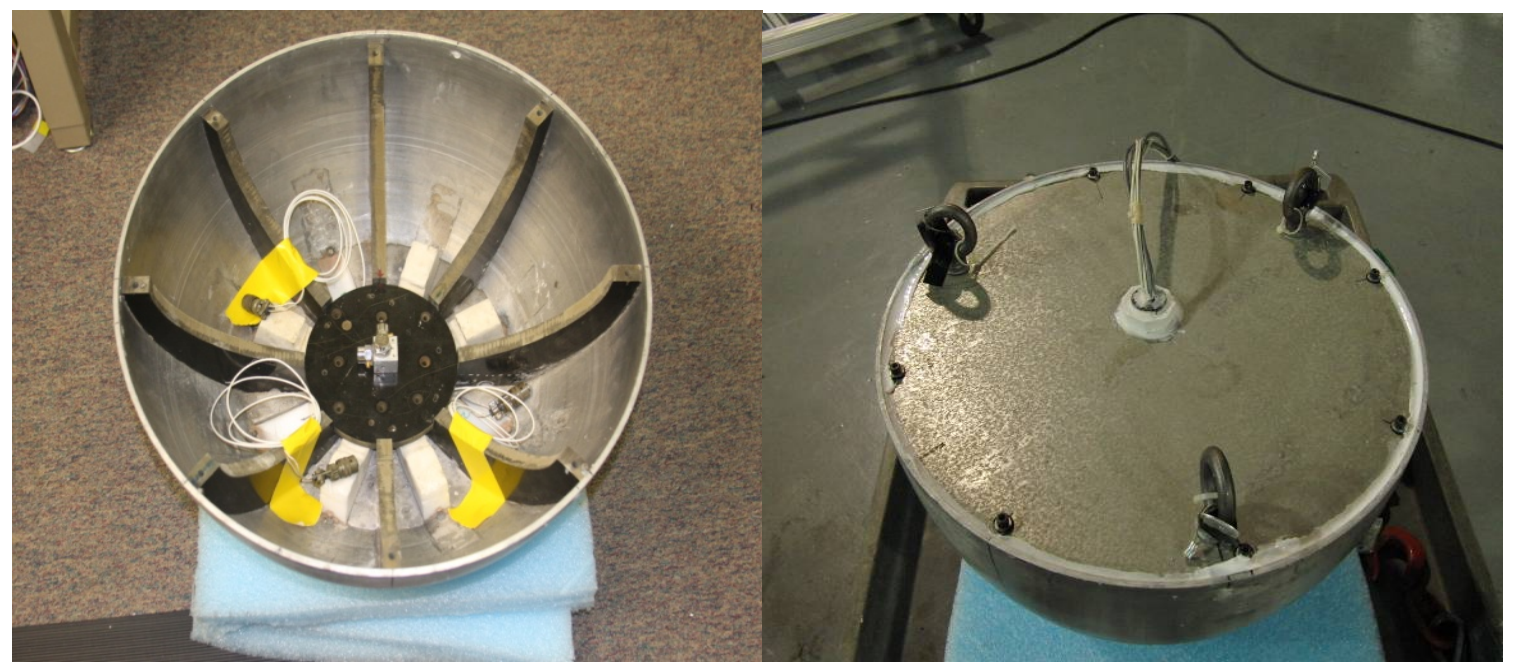

Figure 2. Penetrometer Configuration.

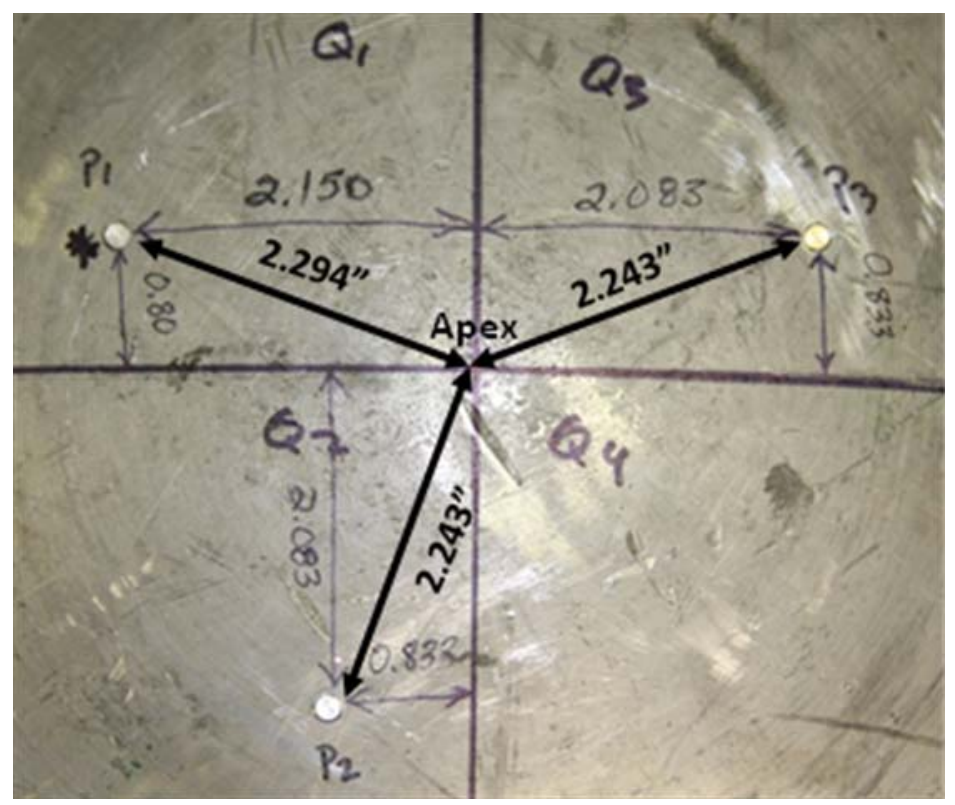

Figure 3. Pressure Transducer Baseline Locations.

\section{B. Impulse Rig}

The impulse rig is illustrated in Figure 4 and was designed to produce a repeatable pressure pulse with a pressure rise time and peak magnitude similar to the water impact tests. The target parameters were a pressure rise rate greater than $1500 \mathrm{psi} / \mathrm{sec}$ and a peak magnitude greater than $100 \mathrm{psi}$. The impulse rig consists of a water-filled cylinder that is closed at one end and is loaded by a piston at the other end. A pressure pulse is created by striking the piston with an impactor. The cylinder has a diameter of approximately 1 inch and a length of approximately 28 inches. Pressure transducers can be installed in ports at five stations along the length of the cylinder. Each station 
features three ports. The impact on the piston is generated using either an impulse hammer with an integrated load cell, or a steel slug dropped through a guide tube. The steel slug is preferred because it provides better repeatability.

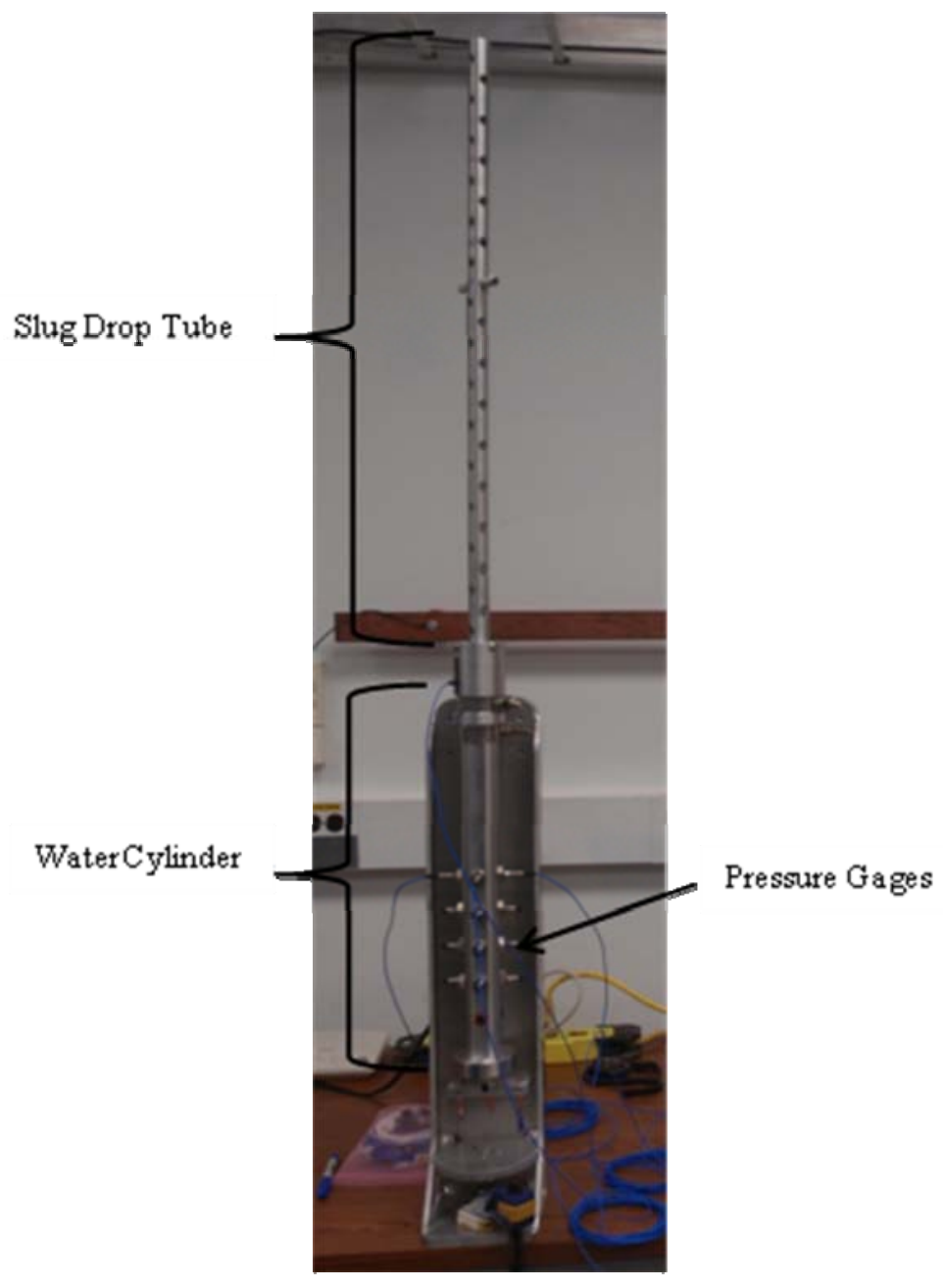

Figure 4. Impulse Rig.

\section{Pressure Transducer Evaluation}

\section{A. Pressure Transducer Type}

Both piezoresistive and piezoelectric pressure transducers are in general use for measuring short duration pressure pulses. The piezoelectric type requires a separate power source. Also, the piezoelectric type exhibits a response that decays with time, which prevents their use for measuring static pressures. Tests were performed using piezoelectric pressure transducers from $\mathrm{PCB}$ Piezotronics, Inc., and piezoresistive pressure transducers from Measurement Specialties and Endevco Corp. Characteristics of the pressure transducers are described in Table 1. 
Table 1. Pressure Transducer Characteristics.

\begin{tabular}{|l|c|c|c|}
\hline \multicolumn{1}{|c|}{ Characteristic } & MS & Endevco & PCB \\
\hline Sensor Type & Piezoresistive & Piezoresistive & Piezoelectric \\
\hline Sensor & Strain Gage Bridge & Strain Gage Bridge & Quartz Crystal \\
\hline Model & EPX-V02-1 Kp & $8510 \mathrm{~B}-500$ & $112 \mathrm{~A} 21,111 \mathrm{~A} 26$ \\
\hline Diameter (inch) & 0.15 & 0.152 & 0.218 \\
\hline Range (psi) & 1000 & 500 & 100,500 \\
\hline Signal Conditioning & No & No & No \\
\hline Circuit Requirements & Balanced Bridge & Balanced Bridge & $\begin{array}{c}\text { Constant Current Power } \\
\text { Supply }\end{array}$ \\
\hline Static/Dynamic & & Static and Dynamic & Dynamic \\
\hline Pressure Limit & Static and Dynamic & $3 \times$ Full Scale & $2 \times$ Full Scale \\
\hline Maximum Useful Frequency & $2 \times$ Full Scale & $500 \mathrm{kHz}$ & $\geq 400 \mathrm{kHz}$ \\
\hline Acceleration Sensitivity & $40 \mathrm{kHz}$ & $0.0004 \mathrm{psi} / \mathrm{g}$ & $<0.002 \mathrm{psi} / \mathrm{g}$ \\
\hline Temperature Sensitivity & Unknown & $0.02 \mathrm{psi} \mathrm{per} 1^{\circ} \mathrm{C}$ & $\leq 2 \% \mathrm{FSO} \mathrm{per} 1^{\circ} \mathrm{F}$ \\
\hline Material of Body & Stainless Steel & Stainless Steel & Stainless Steel \\
\hline
\end{tabular}

\section{B. Pressure Transducer Mounting}

Water impact tests of the 20 -inch penetrometer were performed with the pressure transducers set flush to the surface, protruding 0.03 inches, and recessed 0.03 inches and 0.06 inches. The baseline set of three gages at the 2.25 -inch radius from the apex were mounted vertical relative to the plane of the water surface. All later gages were mounted normal to the shell surface of the penetrometer. The mounting is illustrated in Figure 5. Pressure histories for all pressure transducers installed flush are shown in Figure 6. Pressure histories for a mix of protruding and recessed pressure transducers are shown in Figure 7. Recessing the pressure transducers 0.06 inches resulted in an oscillatory response, as illustrated in Figure 8. The data shown in Figure 8 is not ideal in that it exhibits flat peaks due to range saturation, but it does illustrate the phenomenon of an oscillatory response due to an excessively large recess. Relative to pressure transducers installed flush to the penetrometer surface, protruding pressure transducers consistently read low, and recessed pressure transducers consistently read high.

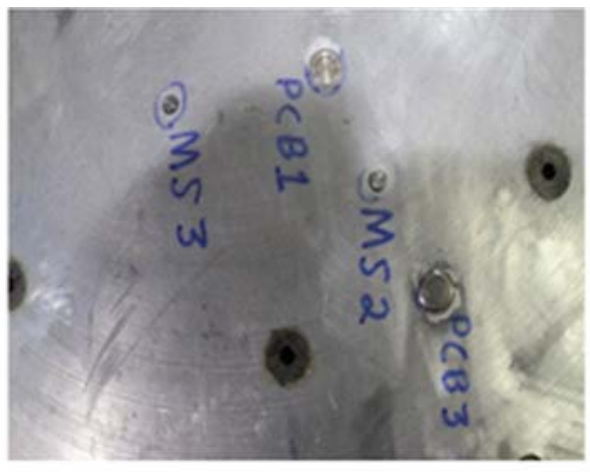

Sensors m ounted flush to OML

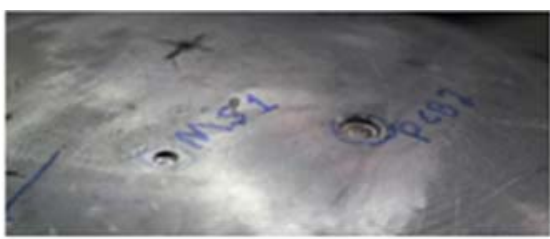

Sensors m ounted recessed $-0.03 "$

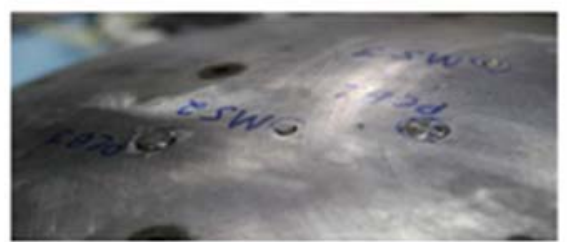

Sensors m ounted protruding $+0.03 "$

Figure 5. Pressure Transducers Mounted Flush, Recessed, and Protruding. 


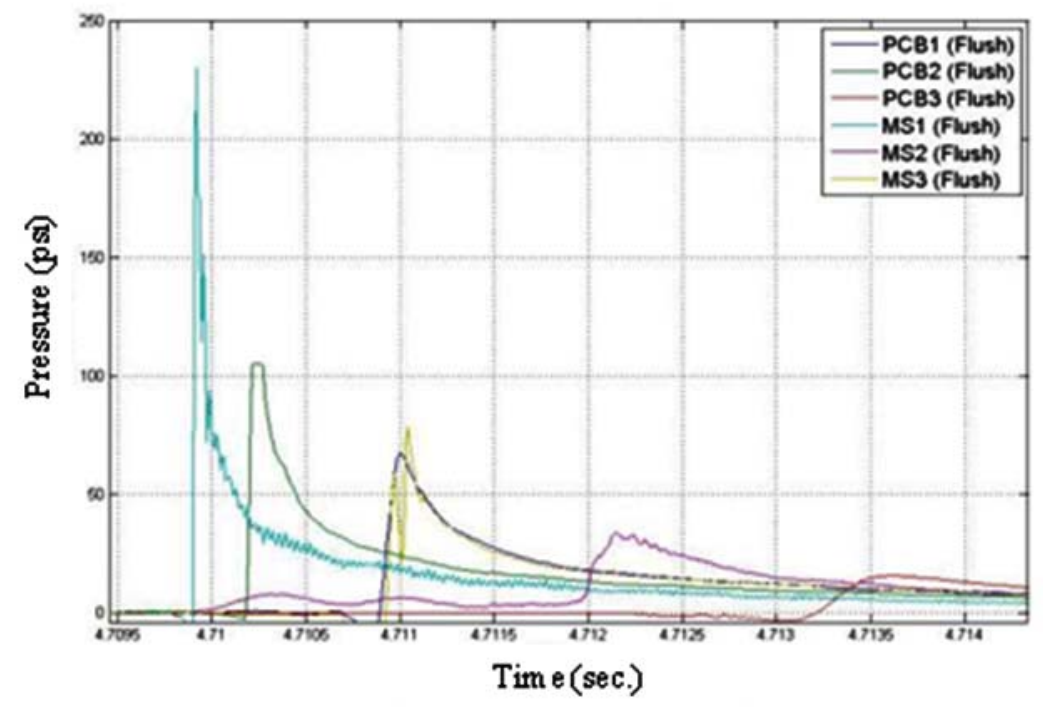

Figure 6. Response of Pressure Transducers Flush Mounted.

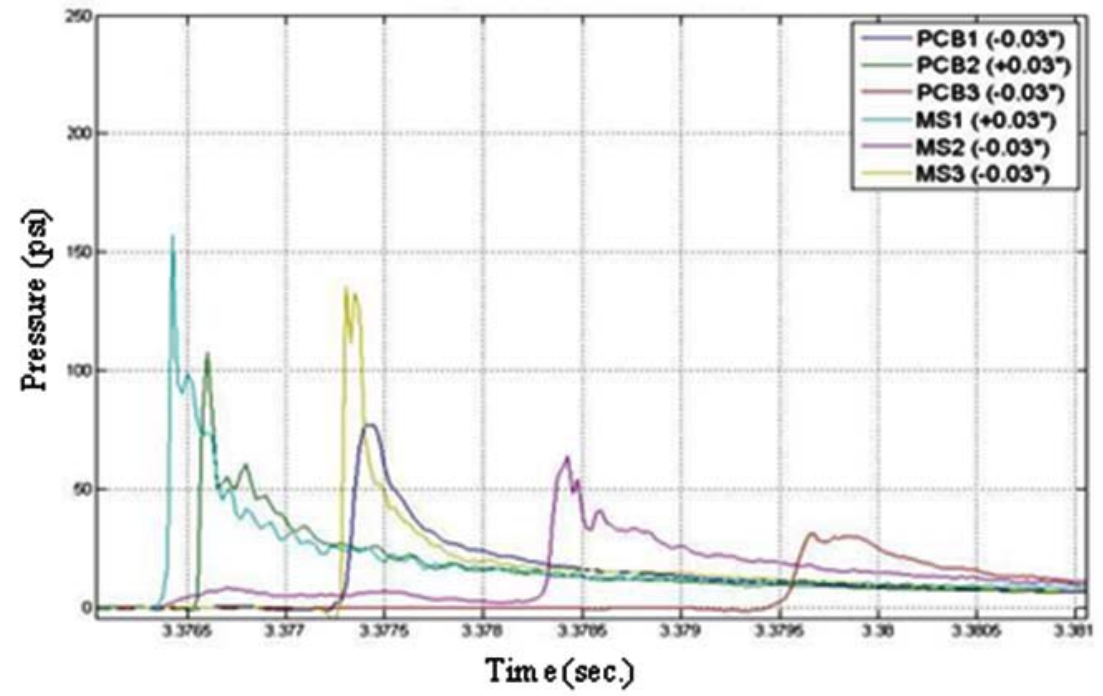

Figure 7. Response of Pressure Transducers Protruding and Recessed. 


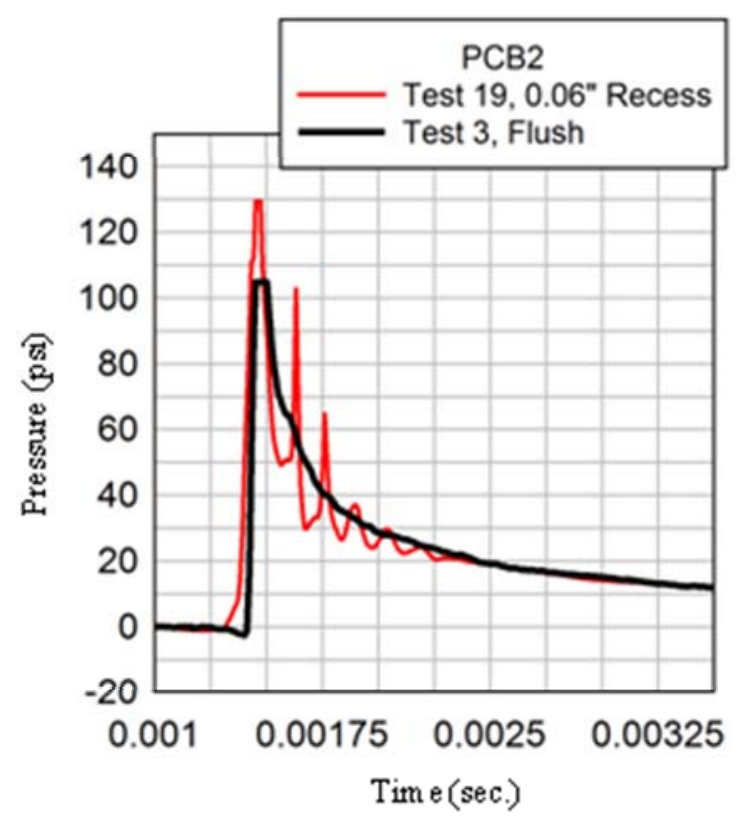

Figure 8. Oscillatory Response for Pressure Transducer Recessed 0.06 inches.

In addition to installing the pressure transducers flush to the surface, the pressure transducer manufacturers recommend that a small gap be maintained around the head so that flexure of the structure does not result in pinching of the head, which would result in a spurious pressure reading. This was not a problem with the penetrometer, which is a very stiff structure, but spurious readings due to pinching has been seen with other test articles that are more flexible. The PCB gages were installed with a bezel made of stainless steel that provided proper clearance and rigidity. Various schemes have been proposed for achieving a smooth flow surface while maintaining a clearance gap, including recessing the pressure transducers slightly and fairing the opening with grease or silicone, but it was found that the grease or silicone attenuate the pressure measurement.

\section{Thermal Shock}

In order to evaluate the effect of thermal shock, a pressure transducer was moved between cups of water at different temperatures while readings were recorded. Figure 9 illustrates readings from one of the MS pressure transducers. The transducers were placed in the cups of water slowly. The response is due solely to thermal effects and does not represent an actual pressure response. The mechanism for the temperature sensitivity is thermal expansion and contraction of the stainless steel transducer sensing surface, which causes deformation in the element underneath. Since heat transfer is involved, the thermal response takes a large fraction of a second to become evident. This places the thermal shock response well after the pressure pulse seen from a water impact. As a consequence, thermal shock is not of great concern in measuring the water impact pressures. Compared to the other pressure transducers, the Endevco gages showed negligible thermal shock response. 


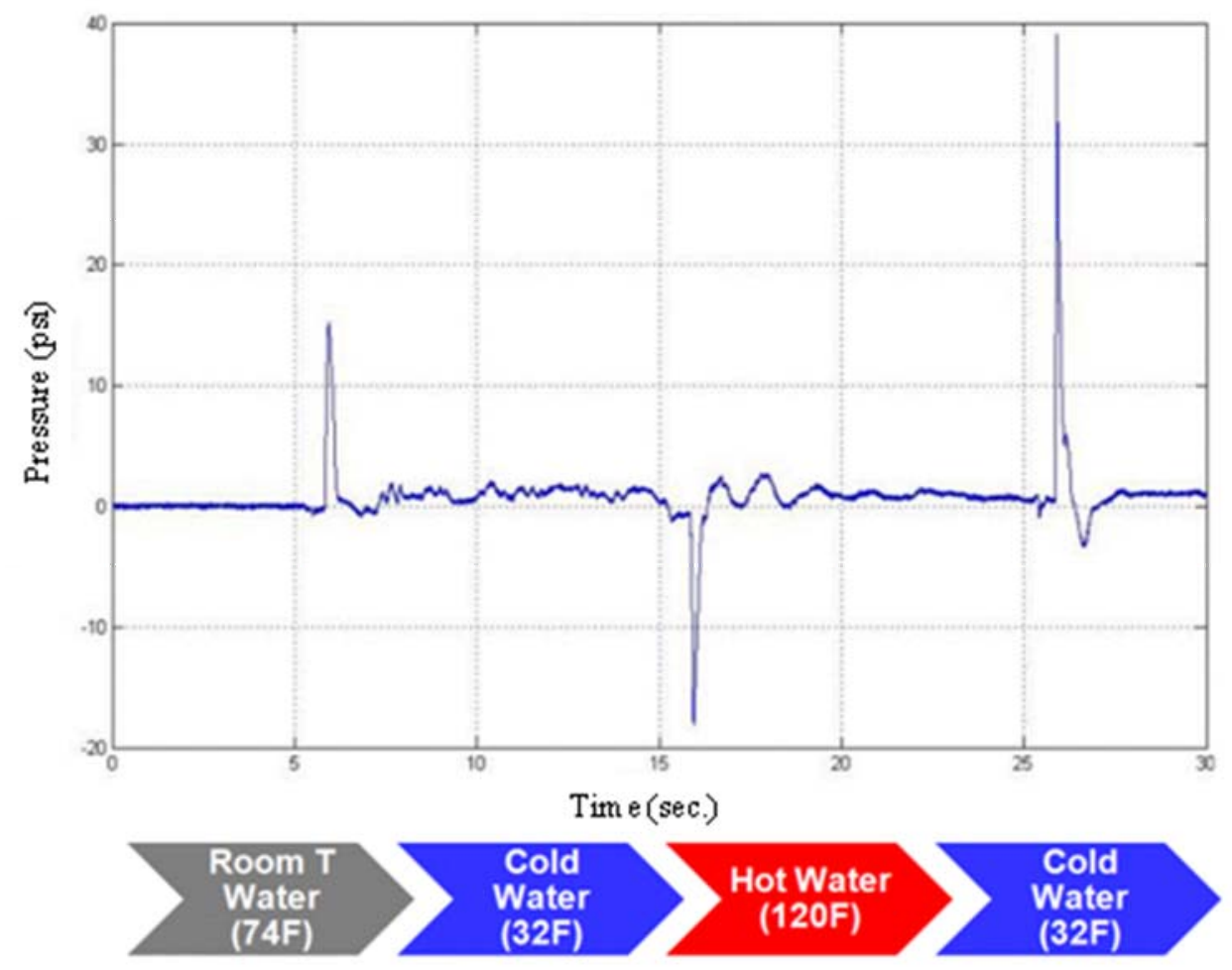

Figure 9. Thermal Shock Response.

The pressure transducer manufacturers recommend that the pressure transducers be recessed slightly with the opening fared with grease or silicone to provide a layer of thermal insulation; however, it was found that the grease or silicone would have some effect in attenuating the pressure measurement.

\section{Data Acquisition Rate}

The data acquisition rate (sampling rate) can have a significant effect on the pressure histories. Figure 10 shows a comparison between pressure histories from the impulse rig measured with an Endevco pressure transducer with sampling rates of $20 \mathrm{kHz}, 40 \mathrm{kHz}$, and $100 \mathrm{kHz}$. No anti-aliasing filter was used for the measurements. For reference, an oscilloscope recording of the response of a PCB pressure transducer is shown that was sampled at 250 $\mathrm{kHz}$. In general, the $20 \mathrm{kHz}$ and $40 \mathrm{kHz}$ sampling rates were found to lose resolution of the peaks and valleys of the pressure histories. This was also true for the penetrometer water impact tests, as shown in Figure 11. The pressure histories were recorded for different tests using a PCB pressure transducer. There is some variability in the impact conditions, so the pressure peak magnitudes vary, particularly for Test \#6. Of primary interest in the comparison is the difference in the number of points that resolve the rise time and the peak. The measurement of the pressure rise time and peak magnitude is degraded for sampling rates less than $40 \mathrm{kHz}$. 


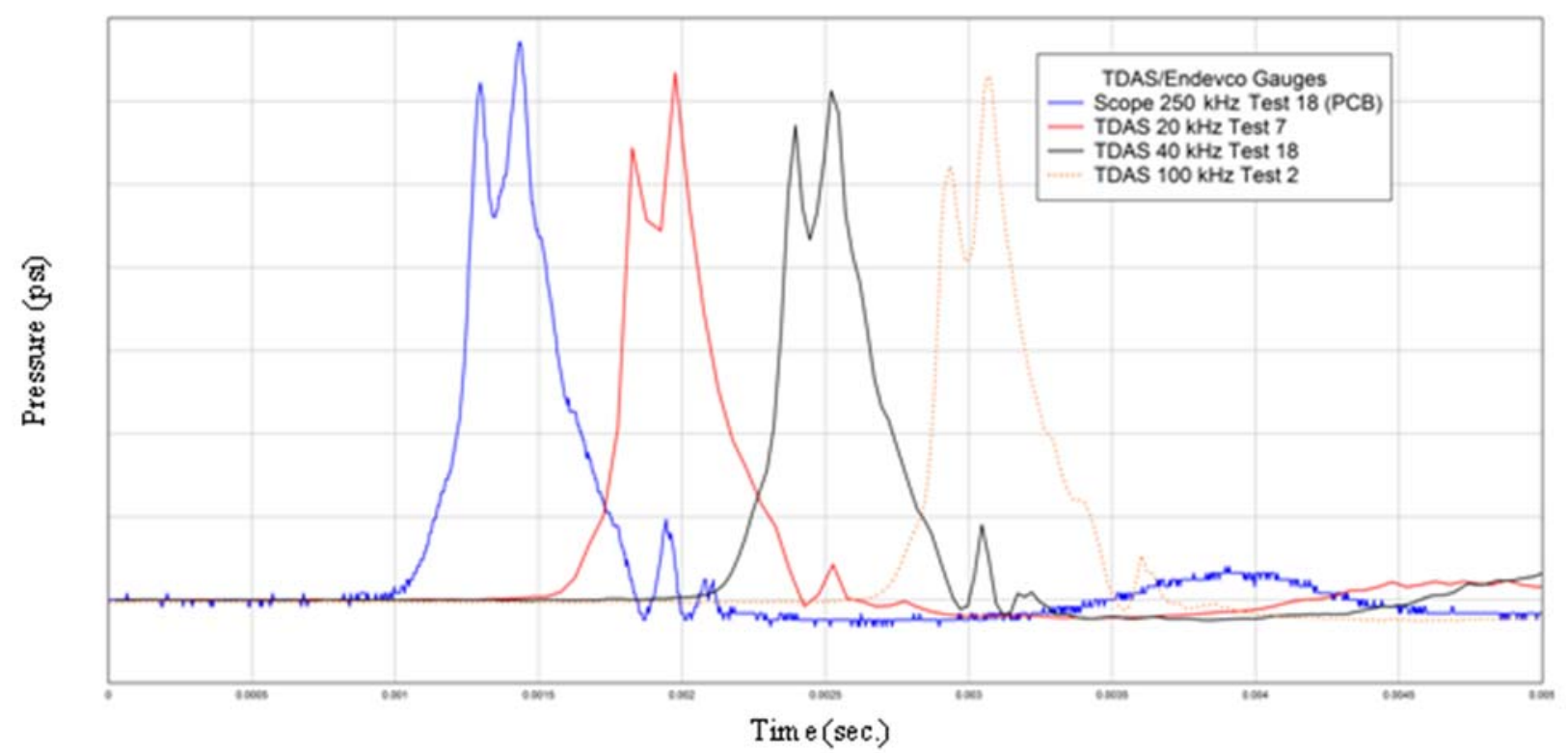

Figure 10. Sampling Rate Comparison for Endevco Pressure Transducers in Impulse Rig.

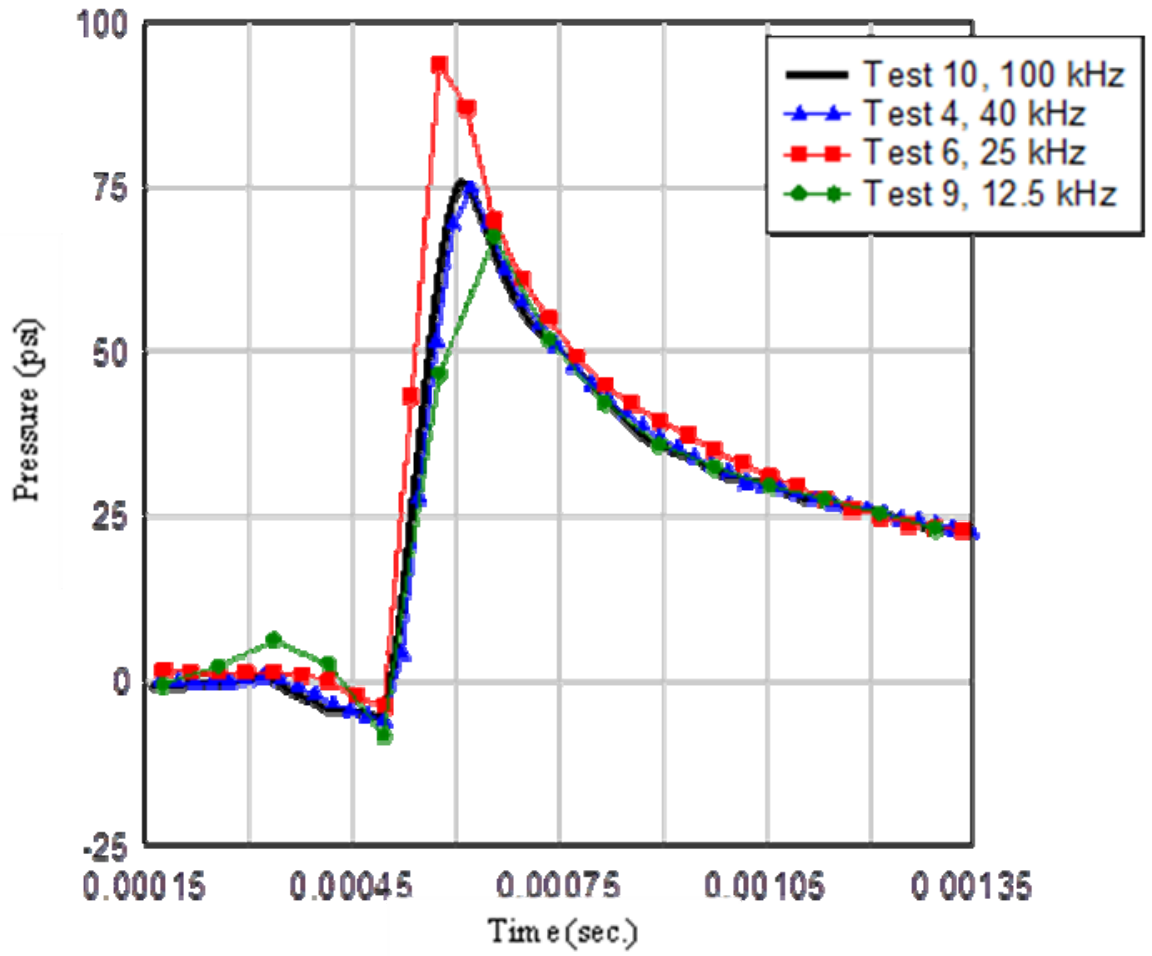

Figure 11. Sampling Rate Comparison for PCB Pressure Transducers in Penetrometer Water Impact Tests.

\section{E. Filtering}

Standard practice within the Structural Dynamics Branch of NASA Langley Research Center is for anti-aliasing filters to be used on all instrumentation channels. There is no single standard for the anti-aliasing filters used on different data acquisition systems. Two data acquisition systems were used for the tests described in this paper along with an oscilloscope. A DTS TDAS PRO was used that features a built-in $4300 \mathrm{~Hz}$ analog filter. The default settings feature the filter active; however, the filter can be switched off. The TDAS sensor input standalone data 
recorder modules have an overall bandwidth limit of approximately $25 \mathrm{kHz}$, and inherently attenuate signals above this. An EME system was also used that features an anti-aliasing filter with a $3 \mathrm{~dB}$ attenuation at $10 \mathrm{kHz}$. The filtering does have consequences for the measurement of pressure histories in water impact problems, as illustrated in Figure 12. The data was collected from two different tests with a PCB pressure transducer sampled at $40 \mathrm{kHz}$ using the TDAS. There is some variability in the impact conditions, which could be partly responsible for the difference in the peak pressure magnitudes, but the large difference in the pressure rise rate is attributed directly to the anti-aliasing filter.

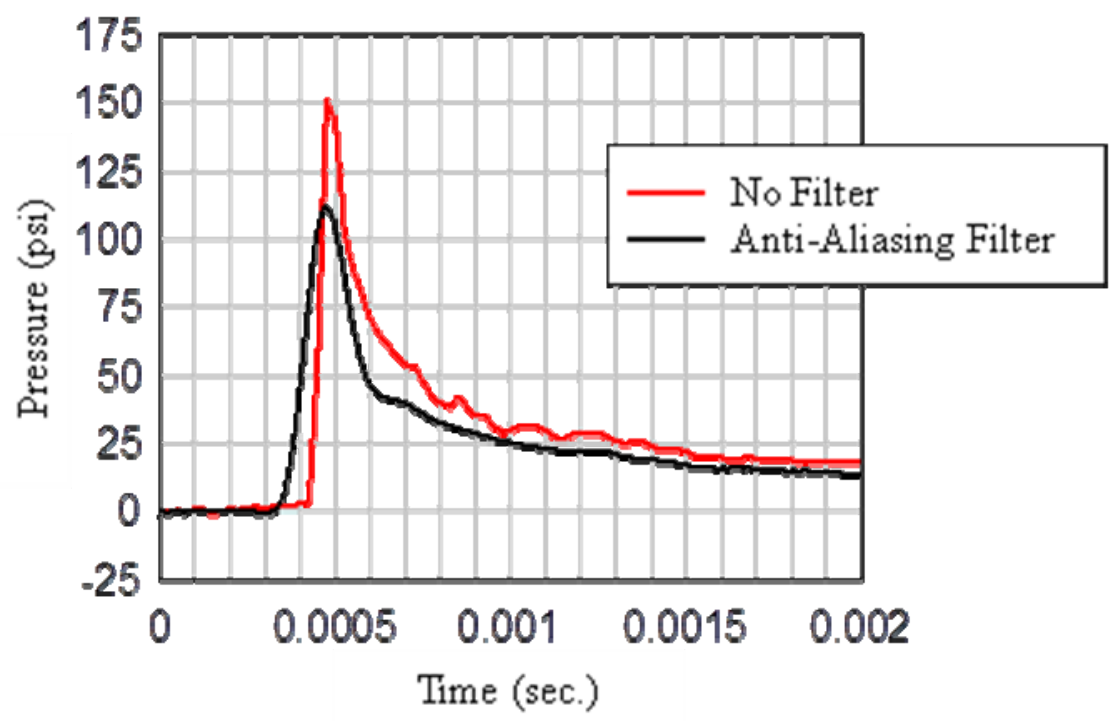

Figure 12. Penetrometer Water Impact Pressure Histories with and without $4300 \mathrm{~Hz}$ Anti-Aliasing Filter.

This raises the issue of whether truly unfiltered data can ever be measured. There are unavoidable aspects of the pressure measurement system that introduce filtering:

1. The pressure transducers are electro-mechanical devices and the circuitry of the data acquisition system has capacitance and inductance, which will result in a maximum response rate for the measurements system, which will have an effect similar to a high frequency filter.

2. The pressure transducer heads have a finite diameter, which will have the effect of averaging the pressure magnitude over a finite area.

Regarding the averaging of the pressure pulse over a finite area, the smaller Endevco and MS pressure transducers have a head diameter of approximately 0.15 inches. Comparison of the arrival time for pressure transducers at different locations shows that the pressure pulse is moving across the penetrometer at a rate of approximately $900 \mathrm{in} / \mathrm{sec}$. The time duration of the upper half of the pressure pulse is approximately 0.2 milliseconds. Based on this, the physical width of the upper half of the pressure pulse is approximately 0.18 inches, which is similar to the size of the head of the pressure transducer. As a consequence, the area of the pressure measurement can be expected to have a significant averaging effect that will result in a reduction in the measurement of the pressure peak.

\section{F. Off-Axis Pitch}

Examination of the impact conditions for the 20 -inch penetrometer highlights the need for a more controlled test that creates a more repeatable pressure pulse, such as the impulse rig. The penetrometer is free to pitch prior to impacting the water. Any pitch angle results in the initial impact location being offset from the apex, which affects both the timing of the arrival of the pressure pulse at each pressure transducer, and the peak magnitude of the pressure reading. In each test, the pressure transducer closest to the impact point registers the first and highest reading. Figure 13 shows the location of the initial impact point relative to the apex for two different tests as determined from onboard rotation rate sensors and collaborated by high-speed video. The pressure transducer 
closest to the apex was MS1 for Test \#2 and MS3 for Test \#7. The corresponding pressure histories are shown in Figures 14 and 15.

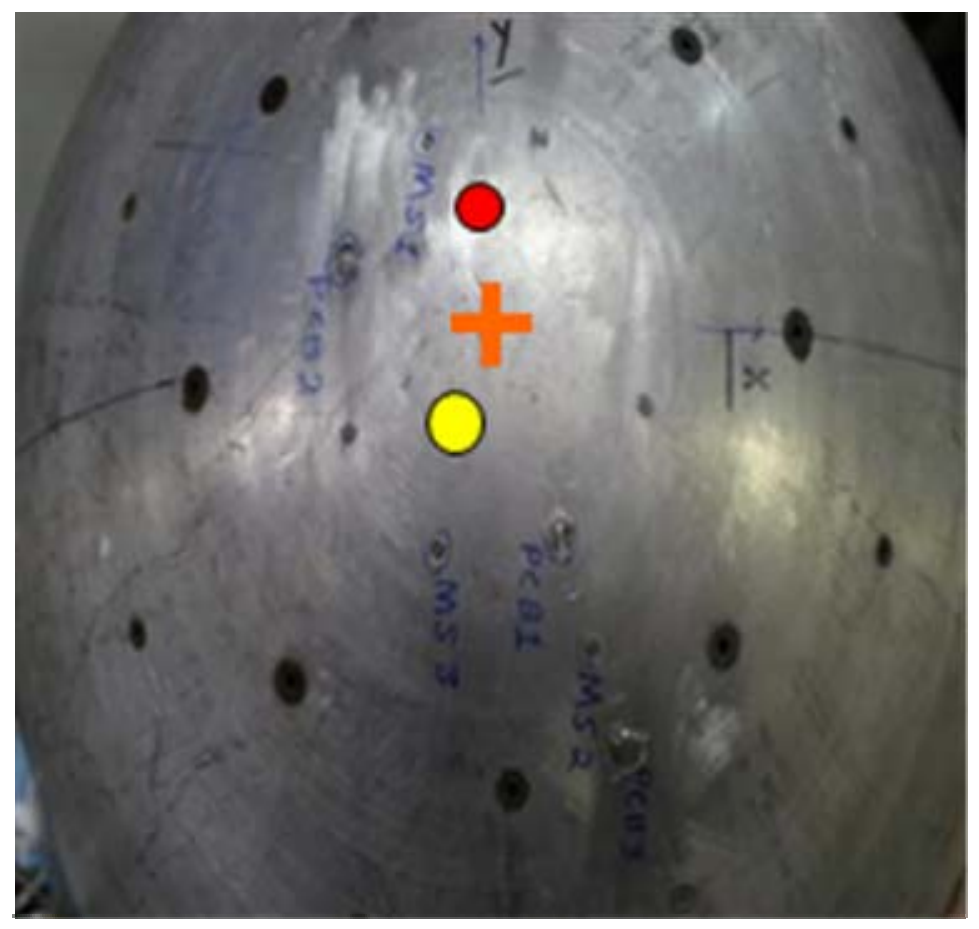

Figure 13. Location of Initial Impact for Test \#2 (Red Dot) and Test \#7 (Yellow Dot) Relative to Apex (Orange Cross).

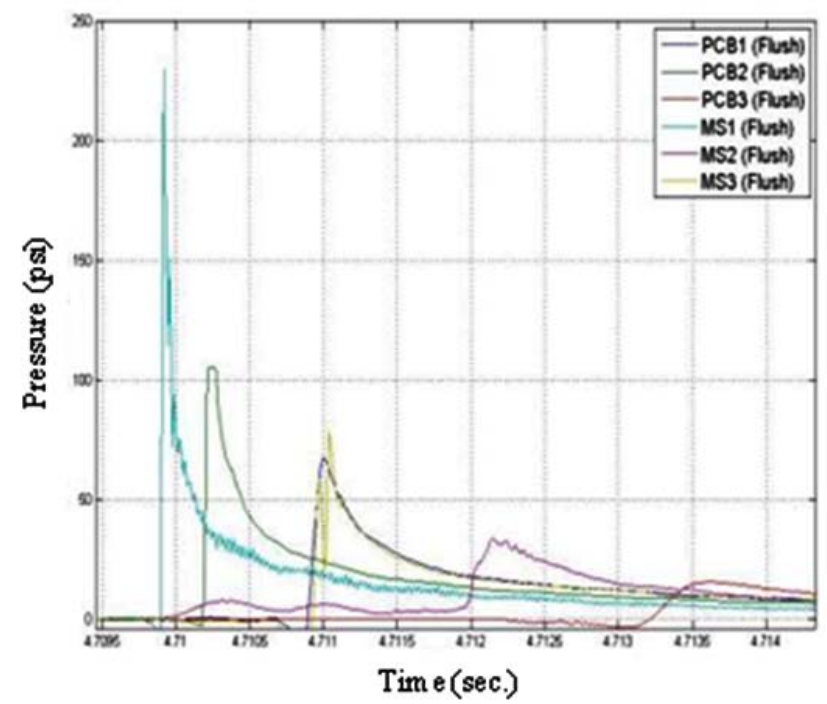

Figure 14. Pressure Histories for Test \#2. 


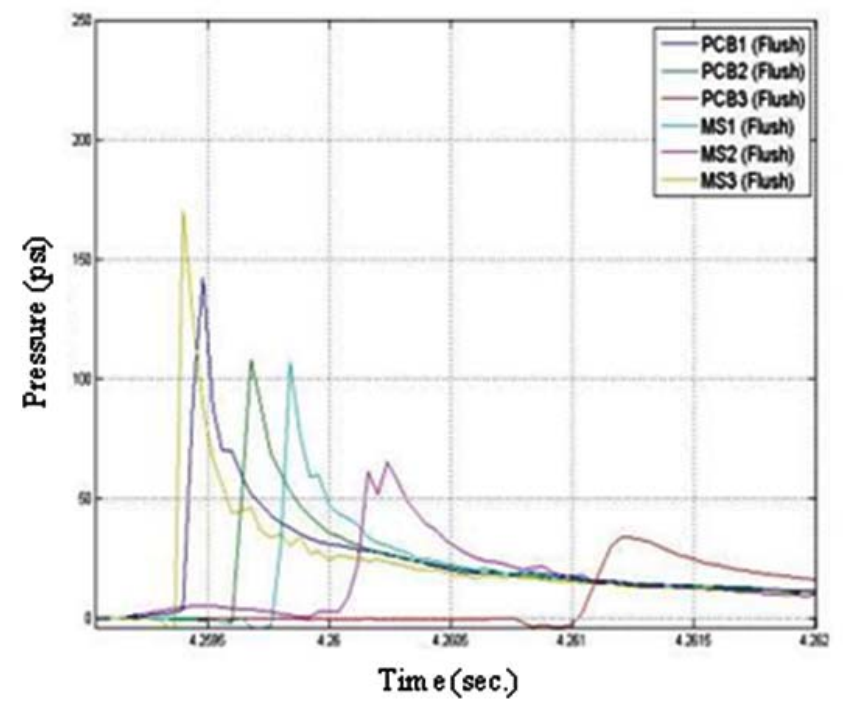

Figure 15. Pressure Histories for Test \#7.

\section{G. General Performance Capability}

The PCB, MS, and Endevco pressure transducers were found to provide peak responses that compared closely, though the MS pressure transducers did occasionally register "dropouts", or short gaps in the output data. The close comparison between the peak responses was demonstrated using the impulse rig. Figure 16 shows a comparison of the response for PCB and Endevco pressure transducers with a $100 \mathrm{kHz}$ sampling rate and no anti-aliasing filter.

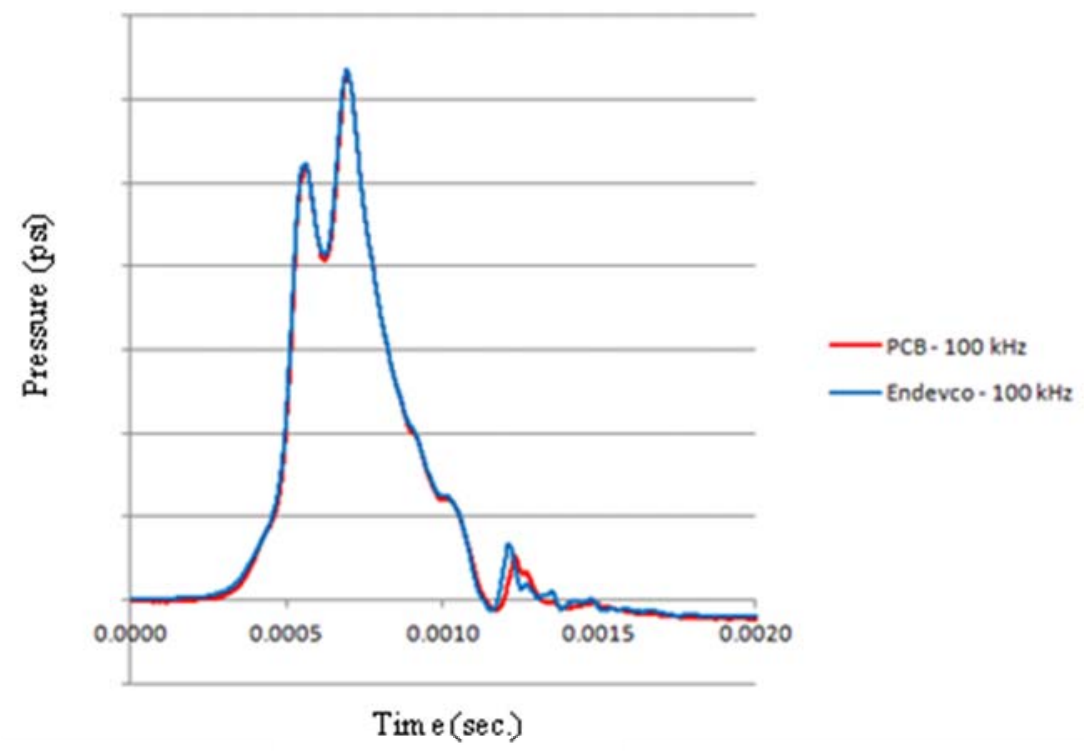

Figure 16. Comparison of Pressure Histories from PCB and Endevco Pressure Transducers in Impulse Rig.

Significant concern exists regarding the ability of the pressure transducers to return to zero reading following a water impact event. Figure 17 shows a comparison of the long duration response from MS and Endevco pressure transducers during a penetrometer water impact. Both the MS and Endevco pressure transducers are piezoresistive devices capable of reading static pressure. The MS pressure transducers show a significant negative pressure following the initial pressure peak. The Endevco pressure transducers do not show any similar negative rebound. This result occurred for the MS pressure transducers only when connected to the TDAS, and did not recur when the MS pressure transducers were connected to the EME. The negative rebound cannot be explained by thermal shock 
effects as the water temperature and air temperature were the same to within approximately $1^{\circ} \mathrm{F}$. Also, the negative pressure persists for several seconds, long after the effects of thermal shock would have dissipated. The rebound does not necessarily imply inaccuracy of the pressure readings during the impact event, but it is a concern for the later time pressure response.

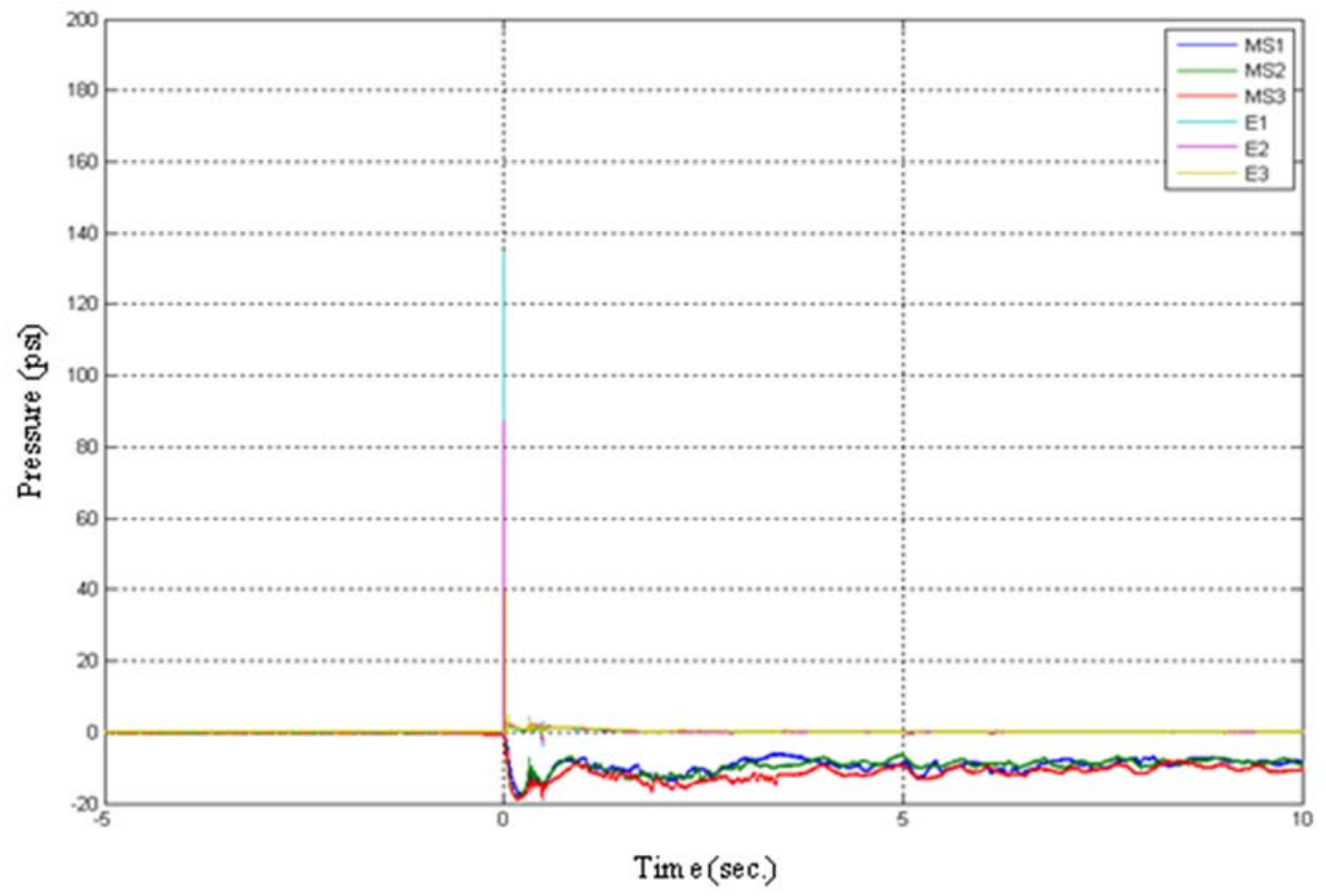

Figure 17. Negative Rebound Pressure Observed for MS Pressure Transducers.

\section{Comparison with Analytical Data}

\section{A. Water Impact Test Data}

To generate data for comparison against an analytical solution, three water impact tests of the 20-inch hemispherical penetrometer were performed at a 5 -foot drop height and three were performed at a 10-foot drop height. Histories from the pressure transducers for the 5-foot and 10-foot drops are shown in Figure 18. MS piezoresistive pressure transducers were used. The sampling rate for the test data was 50,000 Hz. The TDAS data acquisition system was used with the $4300 \mathrm{~Hz}$ anti-aliasing filter.

One pressure history from each test that does not show a truncated peak was chosen for comparison against an analytical solution. The chosen pressure histories are Gage 3 of Test 1, Gage 3 of Test 2, and Gage 2 of Test 3 for the five-foot drops, and Gage 1 of Test 4, Gage 2 of Test 5, and Gage 3 of Test 6 for the ten-foot drops. The peaks of the pressure histories do not occur simultaneously due to small angles of pitch that exist upon impact of the penetrometer with the water. In the figures, the relative timing of the peaks for any given test is as they occurred during the test. For comparisons between tests, the pressure histories have been arbitrarily shifted so that several peaks from different test align. 


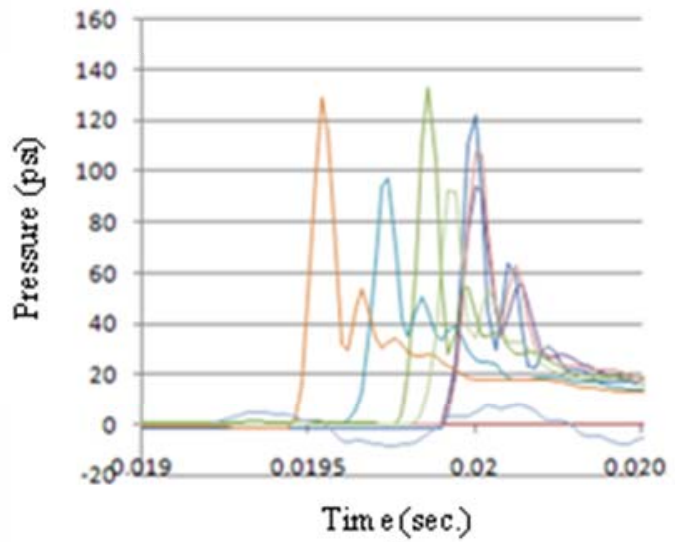

(a)

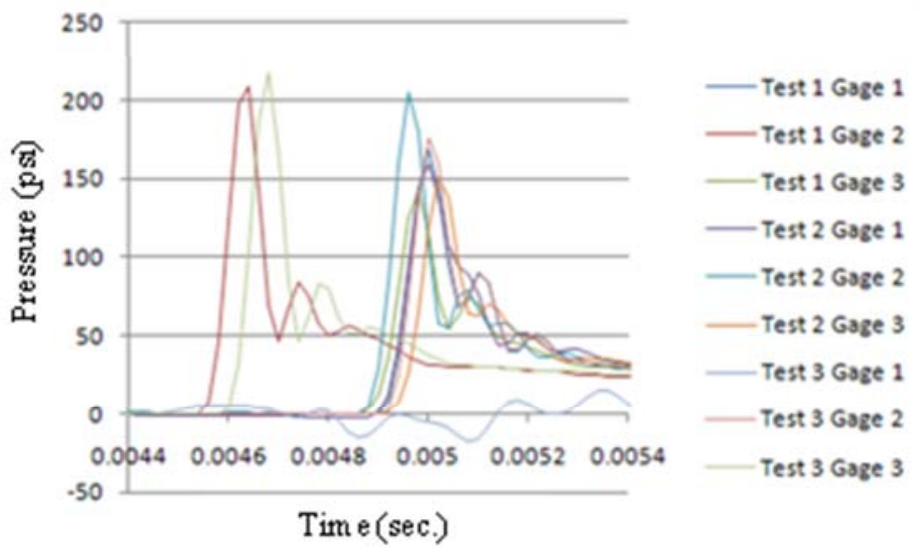

(b)

Figure 18. (a) Pressure for 5-foot Drops and (b) Pressure for 10-foot Drops.

\section{B. Comparison to Analytical Solution}

A closed-form solution for the acceleration and pressure histories of a sphere impacting water has been developed by A.P. Cappelli and J.P.D. Wilkinson [ref. 1]. The equations are as follows:

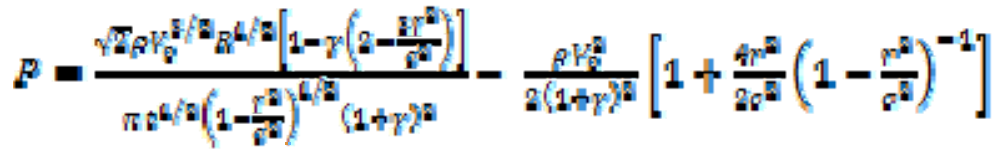$$
\theta=\left(2 R V_{0} t\right)^{1 / 2}
$$

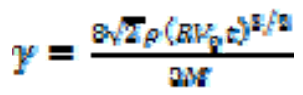

Where: $\quad P=$ Pressure

$$
\begin{aligned}
& \rho=\text { Water Mass Density } \\
& V_{Q}=\text { Initial Impact Velocity } \\
& M=\text { Mass } \\
& R=\text { Radius of Curvature at Impact Point } \\
& r=\text { Polar Distance from Impact Point } \\
& c=\text { Maximum Radius of Wetted Shell Surface } \\
& t=\text { Time after Impact } \\
& \gamma=\text { Non-Dimensional Parameter }
\end{aligned}
$$

Cappelli and Wilkinson note problems with the pressure equation. The predicted pressure is singular at the time that the contact patch radius, $c$, reaches the polar distance, $r$, which results in the equation producing no real answer for the highest pressure at a given polar distance. Cappelli and Wilkinson recommend dropping the second term of the pressure equation as it is small everywhere except for a negative singularity at the perimeter of the contact patch. 
Cappelli and Wilkinson further note that the remaining term of the pressure equation predicts nonphysical negative pressure in the late time.

The closed-form solution pressure histories are plotted in Figure 19 with test data chosen to represent each test as noted above. The closed-form solution is asymptotic at the perimeter of the contact patch, but provides a reasonable prediction of the pressure decay. In the figures, the peak pressure has been limited to the acoustic pressure, $\mathrm{P}=\rho \mathrm{C} \mathrm{V}_{0}$, where $\mathrm{C}$ is the velocity of sound in water.

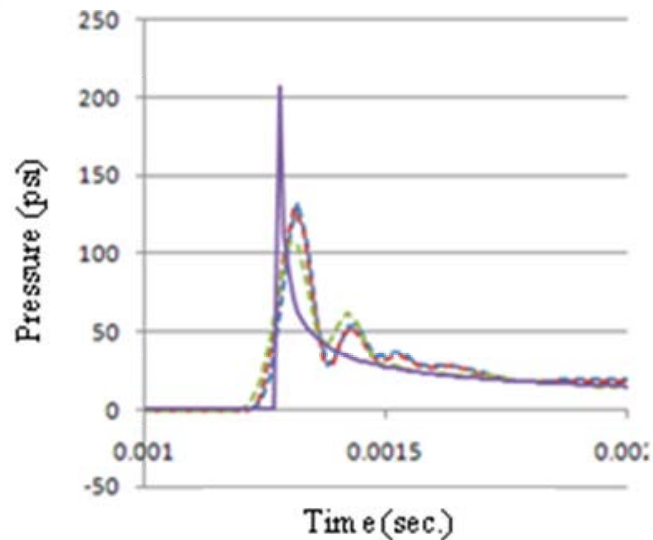

(a)

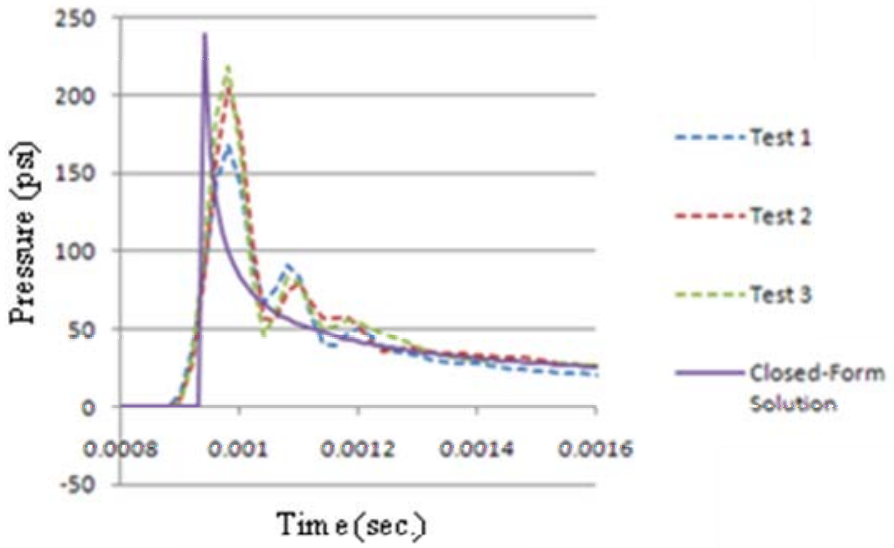

(b)

Figure 19. (a) Closed-Form Solution Pressure for 5-foot Drop and (b) Closed-Form Solution Pressure for 10-foot Drop.

As has been noted previously, the pressure pulse measurement is subject to averaging of the pressure wave over the area of the pressure transducer head, and the filtering of the data acquisition system. To demonstrate this, the solution from the Cappelli \& Wilkinson solution for a 5-foot drop height has been time averaged based on the assumption of a pressure wave moving at $965 \mathrm{in} / \mathrm{sec}$ across a transducer surface. The velocity is based on a vertical velocity of $215 \mathrm{in} / \mathrm{sec}$ and surface sloping 12.89 degrees, which is the slope of the penetrometer surface 2.25 inches from the apex. The diameter of the MS and Endevco transducers is 0.15 inches. An assumption is made that the central 0.05 inches is effective in the pressure measurement. Based on this, a running average over 0.05 inches / 965 in $/ \mathrm{sec} \cong 5$.E-5 seconds was computed from the Cappelli \& Wilkinson solution. For the tests, the data acquisition system featured a $4300-\mathrm{Hz}$ anti-aliasing filter. Based on this, a $4300-\mathrm{Hz}$ forward pass Butterworth was applied to the time-average of the closed-form solution. The resulting time histories are compared in Figure 20. The area averaged and filtered pressure histories do not duplicate the pressure histories seen in the tests, but they do demonstrate basic mechanisms that will affect the pressure measurement. 


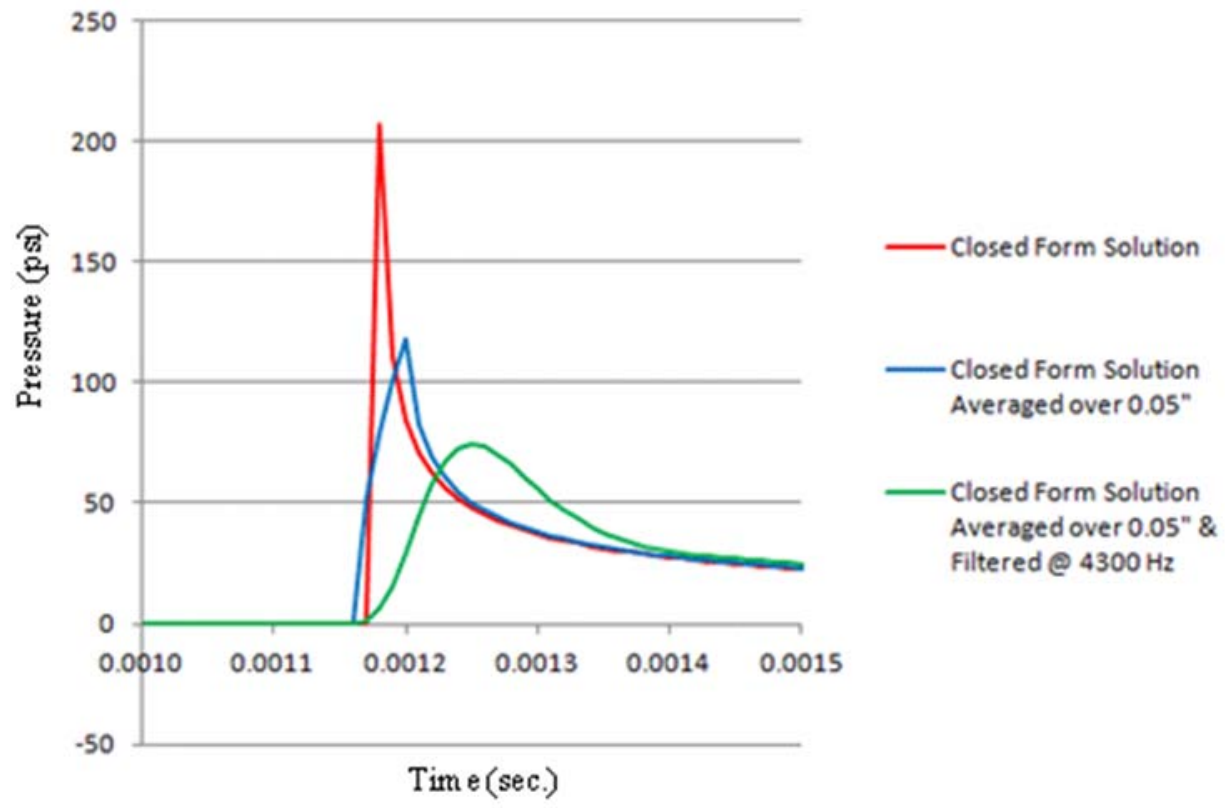

Figure 20. Effect of Finite Pressure Transducer Area and Filtering on Closed Form Solution for Penetrometer Water Impact.

\section{Conclusions}

The following conclusions have been drawn from the test series:

1. Similar measurements of the initial pressure peaks could be obtained with any of the pressure transducers.

2. Flush mounting of the pressure transducer heads is of highest importance as the test data shows that a protruding pressure transducer reads low and a recessed pressure transducer reads high.

3. Thermal shock effects are not important as they occur much later in time than the initial pressure pulse.

4. Failure to return to a zero reading in the late-time may be an issue for some pressure transducer/data acquisition system combinations.

5. A minimum sampling rate of $40,000 \mathrm{~Hz}$ is marginally acceptable.

6. An anti-aliasing filter is not absolutely necessary and, if used, will have some effect on the measurement of the pressure rise time and peak magnitude.

7. Other effects, such as the finite area of the pressure transducer head and overall data acquisition bandwidth, will have an effect equivalent to filtering.

Overall, the Endevco pressure transducers were considered to provide the best performance and demonstrated no significant thermal shock sensitivity. The PCB pressure transducers offered similar performance, except for the thermal shock response. The MS pressure transducers exhibited occasional "dropouts", or gaps in the output data, and produced negative pressure measurements following rebound from the peak response depending on which data acquisition system was used.

\section{Acknowledgments}

This paper describes work funded by the NASA Orion Program Office via the Landing and Descent Deceleration Earth Recovery System (LaDDERS) and Structural Passive Landing Attenuation for Survivability of Human Crew (SPLASH) projects, and by the NASA Engineering Safety Center (NESC) via the Crew Module Water Landing Modeling Assessment (CMWLMA) project. The authors would like to thank the following people for their contributions to the program: 
Mr. Ronald Baccus/NASA JSC

Mrs. Lynn Bowman/NASA LaRC

Mr. Steven Gayle/NASA LaRC

Mrs. Karen Lyle/NASA LaRC

Mr. Michael Kelly/NASA LaRC

Mr. John Baker/NASA JPL

\section{References}

${ }^{1}$ Cappelli, A.P. and Wilkinson, J.P.D., "Study of Apollo Water Impact, Final Report, Volume 2, Dynamic Response of Shells of Revolution during Vertical Impact into Water - No Interaction," NASA CR 92020, North American Aviation, Inc., Space Division, May 1967. 